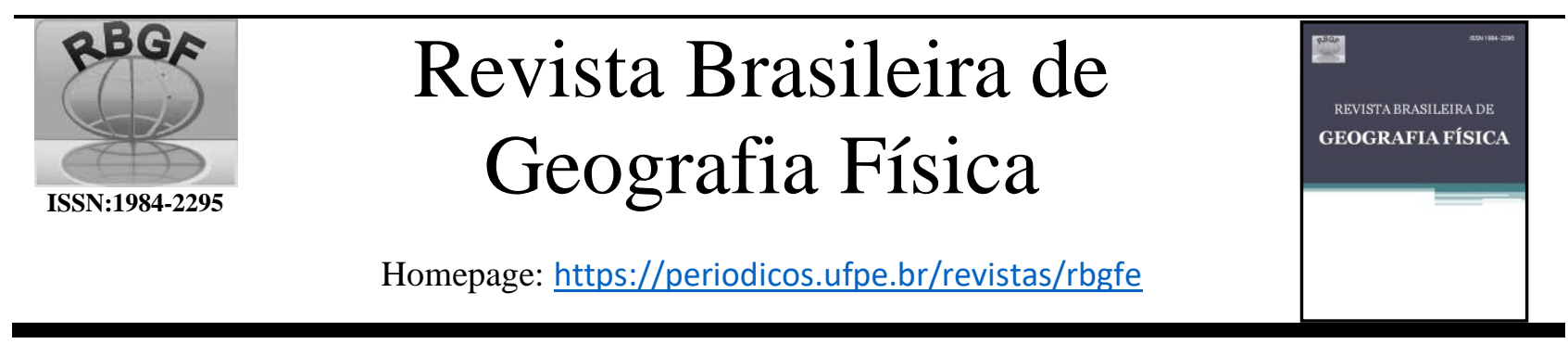

\title{
Caracterização de eventos extremos e de suas causas climáticas com base no Índice Padronizado de Precipitação Para o Leste do Nordeste
}

Djane Fonseca da Silva1, Maria José da Silva Lima², Pedro Fernandes de Souza Neto ${ }^{3}$, Heliofábio Barros Gomes $^{4}$, Fabrício Daniel dos Santos Silva ${ }^{4}$, Henrique Ravi Rocha de Carvalho Almeida ${ }^{5}$, Marcos Paulo Santos Pereira $^{6}$, Rafaela Lisboa Costa ${ }^{7}$

${ }^{1} \operatorname{Prof}^{\mathrm{a}} \mathrm{Dr}^{\mathrm{a}}$ do Instituto de Ciências Atmosféricas - ICAT/UFAL, Campus A. C. Simões, Maceió (AL), e-mail: djane.silva@icat.ufal.br (autor correspondente); ${ }^{2}$ Mestranda em Meteorologia - ICAT/UFAL, e-mail: maryah_lima@ hotmail.com; ${ }^{3}$ Mestrando em Meteorologia - UACA/UFCG, e-mail: piurosfernandes@ hotmail.com; ${ }^{4}$ Prof. Dr. do Instituto de Ciências Atmosféricas - ICAT/UFAL, Campus A. C. Simões, Maceió (AL), e-mail: heliofabio@icat.ufal.br, fabricio.santos@icat.ufal.br; ${ }^{5}$ Prof. Dr. do Centro de Ciências Agrárias - CECA/UFAL, Rio Largo, e-mail: henrique ravi@yahoo.com. $\mathrm{br}^{6}$ Prof. Dr. Visitante no ICAT/UFAL, email:marcospspereira@ hotmail.com; ${ }^{7} \operatorname{Prof}^{a}$ Dr $^{a}$ no Programa PNPD ICAT/UFAL, e-mail: rafaelalisboac@ gmail.com.

Artigo recebido em 19/04/2019 e aceito em 01/04/2020

\section{RE S U M O}

Os eventos climáticos extremos demonstram um papel significativo das sociedades, seja por sua intensidade, pela frequência de ocorrência ou pela vulnerabilidade socioambiental. Objetiva-se classificar e quantificar as precipitações na porção leste da região Nordeste (NE) do Brasil através do índice SPI, como também detectar maiores déficits e/ou excesso de precipitação. O Standardized Precipitation Index (SPI) foi utilizado para quantificar déficits de precipitação e identificar eventos secos e chuvosos em diferentes escalas temporais, auxiliando no monitoramento da sua dinâmica temporal. No cálculo do SPI foi utilizado a distribuição gama, e estimados os limites de precipitação que representam a cada categoria do índice. Foram utilizados dados pluviométricos das capitais dos estados que compõem no leste do Nordeste do Brasil, no período de 1961 a 2014 provenientes da Agência Nacional das Águas (ANA). A análise de Ondeletas foi utilizada com objetivo de identificar ciclos de extremos pluviométricos e de suas causas através das escalas temporais detectadas em séries de precipitação para as capitais do leste do Nordeste do Brasil. Os resultados mostraram que as ocorrências de secas foram as maiores em todas as cidades, todavia na categoria extrema os eventos chuvosos revelaram-se mais frequentes. Os anos normais foram os mais persistentes em todas cidades analisadas. Recife apresentou máximas ocorrências de eventos chuvosos. Os eventos com intensidade extrema, seja chuvoso ou seco, ocorreram em boa parte da série em anos de ENOS. O SPI revelou-se uma excelente ferramenta na deteç̧ão e no monitoramento de seca/chuvas na região analisada. A presença de escalas temporais relacionadas com eventos ENOS, Dipolo do Atlântico, ciclo de manchas solares e Oscilação Decadal do Pacífico foram identificadas em todas as capitais do leste do NEB.

Palavras chaves: SPI; chuva extrema; secas; Análises de Ondeletas.

\section{Characterization of Drought Events Based on the Standardized of Precipitation Index for the East Northeast}

A B S T R A C T

Extreme weather events demonstrate a significant role for societies, whether by their intensity, frequency of occurrence or socio-environmental vulnerability. Objective-classify and quantify as precipitation in the eastern portion of the Northeast (NE) of Brazil through the SPI index, as well as detect larger deficits and / or excess occurrence. The Standardized Precipitation Index (SPI) was used to quantify use deficits and to identify dry and rainy events in different temporal variations, helping to monitor their temporal utilization. No SPI calculations were used for gamma distribution, and estimated capture limits representing each category of the index. Rainfall data were used from the capitals of the states that make up the eastern Northeast of Brazil, with no period from 1961 to 2014, Registration of the National Water Agency (ANA). A wave analysis was used to identify extreme rainfall cycles and their causes caused by temporary variations detected in monitoring series for the eastern capitals of Brazil. The results shown as drought occurrences were the highest in all cities, however in the extreme category of rain events most frequently revealed. The normal years were 
the most persistent in all cities analyzed. Recife presents maximum occurrences of rain events. Extreme intensity events, whether rainy or dry, occur in much of the series in ENSO years. The SPI revealed an excellent tool for detection and monitoring of drought / gloves in the analyzed region. The presence of temporary variations related to ENOS, Atlantic Dipole, sunspot cycle and Pacific Oscillation events are identified in all eastern NEB capitals.

Keywords: SPI; extreme rainfall; drought; Wavelet analysis.

\section{Introdução}

Os eventos climáticos extremos ocorrem de diversas formas, como enchentes, secas prolongadas, ondas de calor, chuvas extremas e etc. Os eventos meteorológicos e climáticos extremos são também um aspecto integrante da variabilidade climática, e sua frequência e intensidade podem variar de acordo com as mudanças climáticas (Marengo, 2016).

Por meio de ciclos, a variabilidade climática, produz deficiência e/ou excesso de chuvas em todo o globo, que por consequência, gera secas ou inundações. Os eventos climáticos de extremas intensidades demonstram um papel significativo no dia a dia das sociedades, seja por sua intensidade e frequência de ocorrência, seja pela vulnerabilidade socioambiental (Santos et al., 2017).

Os eventos extremos têm causado constantes impactos em inúmeras cidades do Brasil nas últimas décadas. Certamente os desastres naturais mais frequentes no país são as estiagens, as inundações e os deslizamentos. Desastres naturais ganharam maior destaque na mídia eletrônica e impressa devido aos impactos socioambientais ocasionados nas grandes áreas urbanas, a citar, elevado número de mortes, feridos e desabrigados, perdas econômicas onerosas, proliferação de doenças, impactos ao meio ambiente, dentre outros (Oliveira et al., 2017; Anjos et al., 2016; Loureiro et al., 2014).

$\mathrm{O}$ elemento do clima que provoca as transformações mais rápidas na paisagem do meio tropical e subtropical é a precipitação pluviométrica, sobretudo durante o verão, como episódios de chuvas concentradas (chuvas intensas ou aguaceiros), que ocorrem todos os anos nessa mesma estação; não raras vezes resultam em tragédias, principalmente na zona costeira e nas grandes cidades (Da Silva, 2017).

Outro evento com severas consequências é a seca, classificada como um fenômeno natural que nitidamente difere de outros, por normalmente apresentar um início lento, uma longa duração e espalhar-se, na maioria das vezes, por uma extensa área (Freitas, 2005 apud Costa, 2015).

Uma vez que a seca é um evento complexo, tendo influência local ou/e regional, estudá-la é de suma importância para o planejamento e gestão dos recursos hídricos, assim, meteorologistas e hidrólogos propuseram índices para detectar, caracterizar e monitorar as secas. Em muitas regiões brasileiras, não há definições dos limites de precipitação para classificação da seca ou umidade em determinada região, e, portanto, os índices de seca podem permitir a detecção, caracterização e monitoramento do fenômeno (Uliana et al., 2015).

Para melhorar a capacidade de detecção e monitoramento secas em diferentes escalas de tempo os autores Mckee et al. (1993) desenvolveram um índice de precipitação padronizado, conhecido como Standardized Precipitation Index (SPI), o qual apresenta vantagens em relação aos demais índices, estando em destaque por permitir a caracterização do déficit ou do excesso de precipitação em uma determinada localidade, com sua flexibilidade temporal e simplicidade, e utilização de apenas dados mensais de precipitação.

A intenção inicial do SPI era apenas de classificar eventos secos, no entanto, alguns autores utilizaram o índice na detecção e monitoramento de eventos chuvosos (Nascimento et al., 2017).

Uliana et al. (2015) estudaram a utilização do índice de precipitação padronizado para a região norte do estado do Espírito Santo, concluíram que o SPI mostra ser um método simples e eficaz para caracterização e monitoramento da seca e da umidade na região norte do estado.

Santos et al. (2014) analisaram a frequência de eventos severos e extremos de seca e de chuva na Amazônia utilizando o SPI nas escalas de 6 e 12 meses para o período de 1925 a 2000. Os autores observaram que as séries temporais dos SPIs, mostraram períodos longos de oscilação entre eventos secos e chuvosos.

Conforme Santos et al. (2017) para se estimar demandas de água no futuro e ainda definir políticas ambientais de uso e gerenciamento de água faz necessário a compreensão sobre possíveis cenários climático-hidrológicos futuros e as suas incertezas.

Tendo em vista o importante papel do conhecimento prévio e subsequente de extremos secos e chuvosos o presente estudo objetiva analisar, e quantificar casos/anos de eventos secos e chuvosos no período de 1961 a 2014, para o leste 
do Nordeste, e identificar suas causas climáticas através das análises de ondeletas.

\section{Matérial e métodos}

Área de estudo e Dados

O Leste do Nordeste (Figura 1) é composto pelos Estados de Alagoas, Bahia, Paraíba, Pernambuco (incluindo o Distrito Estadual de Fernando de Noronha), Rio Grande do Norte e Sergipe. A área da Região Nordeste ocupa $1.561 .177,8 \mathrm{Km}^{2}$, equivalente a $18,3 \%$ do território nacional limita-se a norte e a leste com o Oceano Atlântico, ao sul com os Estados de Minas Gerais e Espírito Santo e a oeste com os estados do Pará, Tocantins e Goiás (Da Silva, 2017).

Segundo dados do Instituto Brasileiro de Geografia e Estatística (IBGE, 2010) a população residente em 2010 era de 53.081.950 habitantes, ou seja, $28 \%$ da população brasileira, e sua densidade demográfica de 34,1 hab./ $/ \mathrm{Km}^{2}$.

A faixa costeira do Leste do Nordeste (ENE) (até $300 \mathrm{Km}$ do litoral) se estende do Rio Grande do Norte ao sul da Bahia, também chamada de Zona da Mata, e apresenta clima tropical úmido com totais pluviométricos anuais variando de 600 a $3.000 \mathrm{~mm}$. O período mais chuvoso vai de abril a julho, com o pico de chuvas em maio.

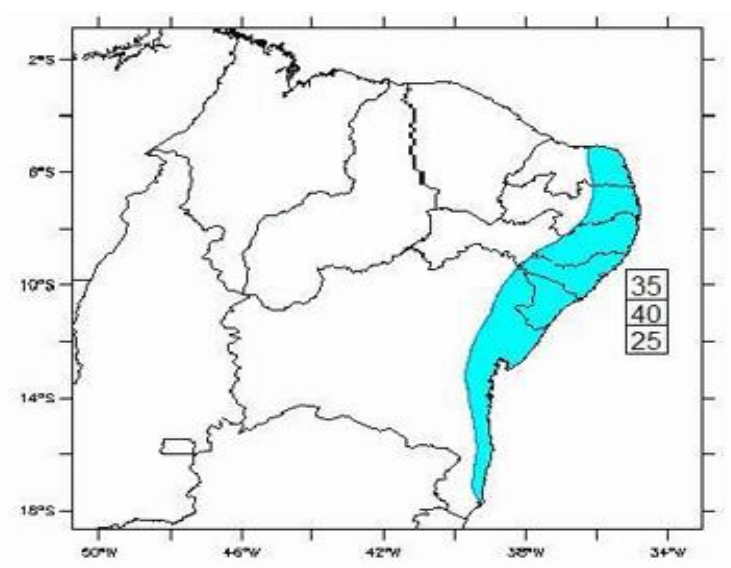

Figura 1- Região Nordeste, em destaque setor Leste do Nordeste. Fonte: CPTEC, (2006).

Foram utilizados dados pluviométricos as capitais que estão no leste do Nordeste do Brasil (Tabela 1), de, no mínimo, 30 anos de dados, provenientes da Agência Nacional das Águas (ANA). A partir desses dados foram geradas as séries de SPI e seus produtos.

Tabela 1: Cidade, posto meteorológico escolhido e suas coordenadas geográficas.

\begin{tabular}{l|l|l|l|l}
\hline Cidade & Código & Lat $\left(^{(}\right)$ & Lon $\left({ }^{\circ}\right)$ & Alt $(\mathbf{m})$ \\
\hline Salvador & 01238045 & $-12,9166$ & $-38,5$ & 10 \\
\hline Aracaju & 01037004 & $-10,09166$ & $-37,05$ & 4,72 \\
\hline Maceió & 00935004 & $-9,55111$ & $-35,77$ & 64,5 \\
\hline Recife & 00834005 & $-8,0333$ & - & 4 \\
\hline João Pessoa & 00734006 & $-7,1$ & $-34,8666$ & 44 \\
\hline Natal & 00535008 & $-5,7666$ & $-35,2$ & 65 \\
\hline
\end{tabular}

\section{Métodos}

Índice de Precipitação Normalizada (SPI)

O cálculo do SPI se inicia determinando uma função de densidade de probabilidade que descreve as séries temporais. A distribuição gama possui bom ajuste para variáveis contínuas que tenham limite inferior ou igual a zero e não possuem limite superior, por isso, é largamente utilizada para o estudo de séries históricas de precipitação (Wilks, 2006 Apud Santos et al., 2017). A função gama é dada por:

Da Silva, D. F., Lima, M. J. S., Souza Neto, P. F., Gomes, H. B., Silva, F. D. S., Almeida, H. R. R. C., Pereira, M. P. S., Costa, R. L. 


$$
\mathrm{g}(x)=\frac{X^{\alpha-1} * e^{\frac{-x}{\beta}}}{\beta^{\alpha} \Gamma(\alpha)} \text { para } X>0
$$

Em que: $\alpha>0$ parâmetro de forma; $\beta>0$ parâmetro de escala; $x>0$, a quantidade de precipitação (mm) e $\Gamma(\alpha)$ a função gama completa. Para estimativa dos parâmetros $\alpha$ e $\beta$ da distribuição gama utilizou-se o método de:

$$
\alpha=\frac{1}{4 A}\left(1+\sqrt{1+\frac{4 A}{3}}\right) \text { e } \hat{\beta}=\frac{\bar{x}}{\alpha}
$$

Sendo $\bar{X}$, a precipitação média e

$$
A=\ln (\bar{x})-\frac{\sum \ln (x)}{n}
$$

Em que: o n é número de observações.

Deste modo, a distribuição acumulativa é então transformada em distribuição probabilidade normal com média igual a zero e desvio padrão igual a um. Em seguida, a probabilidade acumulada de ocorrência de cada valor mensal é estimada. Aplica-se a essa probabilidade a função normal inversa para encontrar o valor do SPI.

Segundo SANTOS et al. (2017), o SPI nada mais é que a diferença da precipitação observada menos a média do intervalo de tempo específico, dividida pelo desvio padrão, conforme equação:

$$
\mathrm{SPI}=\mathrm{Z}_{\mathrm{i}}=\frac{(P i-\overline{P l})}{\sigma i}
$$

Em que, Pi é a precipitação observada; $\bar{P}$ i e $\sigma \mathrm{i}$, são respectivamente, a média e o desvio padrão da série ajustada.

A classificação do SPI é dada por:

Tabela 2: Classificação dos períodos secos e chuvosos do SPI. Fonte: Adaptado de Santos et al. (2017).

\begin{tabular}{c|c}
\hline Valores de SPI & Classes \\
\hline$<-2,00$ & Seca Extrema \\
\hline$-1,99$ a $-1,50$ & Seca Severa \\
\hline$-1,49$ a $-1,00$ & Seca Moderada \\
\hline$-0,99$ a $-0,49$ & Seca Leve \\
\hline$-0,48$ a 0,49 & Quase normal \\
\hline 0,50 a 0,99 & Chuva Leve \\
\hline 1,00 a 1,49 & Chuva moderada \\
\hline 1,50 a 1,99 & Chuva Severa \\
\hline$>2,00$ & Chuva Extrema \\
\hline
\end{tabular}

Análise de Ondeletas (AO)

Os dados foram investigados com a finalidade de identificar períodos cíclicos, variações sazonais e interanuais, e variações aleatórias, usando as ondeletas.

Foram sujeitas às análises de ondeletas a série de precipitação de cada capital leste nordestina, para todo o período de dados. As análises preliminares de ondeletas fornecem uma indicação mais clara de qual escala temporal domina os sistemas meteorológicos ao longo das séries de SPI.

A ondaleta Morlet é complexa e detém características análogos às de sinais meteorológicos, como simetria ou assimetria, e variação temporal brusca ou suave. Segundo a literatura, este é um critério para escolha da função ondaleta (Weng e Lau, 1994; Morettin, 1999, Da Silva, 2017).
Desta maneira foi feita a escolha da função da ondeleta; a ondeleta Morlet possui uma energia finita e representa uma onda modulada por um envelope Gaussiano (ANDREOLI et al., 2004). É dada pela seguinte expressão:

$$
\Psi(t)=e^{-i \omega_{0} \eta} e^{-\eta^{2} / 2}
$$

Em que $\eta=\mathrm{t} / \mathrm{s}$, onde $\mathrm{t}$ é o tempo, s é a escala da ondaleta em função do tempo $(=2 / \mathrm{dt})$ e $\omega_{0}$ é uma frequência não-dimensional (lag1 = 0,7), escolhidos conforme Andreoli et al. (2004); Todos introduzidos no "script" de programação do Software Matlab®.

\section{Resultados e discussão}

$\mathrm{Na}$ classificação dos eventos de precipitações e secas do leste do nordeste do Brasil através da aplicação do índice de SPI, os resultados mostraram que os eventos mensais normais foram os mais frequentes em todas as cidades analisadas, totalizando, em média, 41,24\% dos eventos, entre 
aproximadamente 222 eventos para Recife e chegando ao máximo de 295 eventos para Aracaju, seguidos de eventos de secas.

As quantidades de secas leves e secas moderadas foram maiores que os de chuvas leves e chuvas moderadas; a persistência de secas com intensidade leve requer atenção por parte de gestores, visto que, os eventos menos intensos de secas podem se desenvolver para mais intensos, consoante à atuação de fenômenos externos (Nascimento et al., 2017), contribuindo com possíveis agravamentos nos setores hídrico, e agro econômico. Cabe ressaltar que, todos os episódios de secas leves de cada cidade ultrapassam o total de todas as respectivas chuvas juntas.

As classificações pelo SPI foram utilizadas em vários trabalhos, em diferentes lugares do Brasil: Paraíba (Macedo et al., 2010); Piauí (Guedes et al., 2012); Espírito Santo (Uliana et al., 2015); Bahia (Sousa et al., 2016); Maranhão (Nascimento et al., 2017); Amazônia (Santos et al., 2017); São Paulo (Bonfim \& Da Silva, 2018); assim, todos os autores confirmam que o SPI mostra ser uma importante ferramenta na detecção dos eventos extremos de chuvas/secas.

Ainda, foi possível observar que eventos de chuvas extremas (valores do SPI > 2) foram mais ocorrentes quando comparado aos eventos de secas extremas, complementando Santos et al. (2017). Os casos extremos de precipitação totalizaram em média $28,07 \%$ dos eventos, já os de seca extrema, $1,07 \%$ para todas as cidades, devido ambas as localidades possuírem comportamento climático semelhantes.

Para Bonfim \& Da Silva (2018) as ocorrências de extremos de chuvas acarretam em aumento mais significativo na intensidade e não necessariamente na frequência de eventos de chuvas. Os casos de chuvas leves a extremas se apresentam em menor número, mas com maior intensidade.

Sousa et al. (2016) indicaram que a Bacia Hidrográfica do Rio Paraguaçu apresentou aumento de precipitação, devido à frequência de eventos de precipitação extrema ser maior do que a frequência dos eventos de seca extrema, coincidindo com os resultados aqui encontrados.

A Análise de Ondeleta apresenta a habilidade de detectar diferentes escalas temporais em uma série de dados. Foram identificadas as escalas temporais nas séries pluviométricas das capitais do leste do Nordeste, como também a escala temporal dominante em cada cidade.

A presença de escala temporal de 1 a 2 anos foi observada em todas as capitais, estando associada ao ciclo anual dos sistemas acoplados oceano-atmosfera atuantes na região. Também foi observada variabilidade da precipitação com escala de 7 anos, relacionadas com eventos ENOS estendido e Dipolo do Atlântico, de 11 anos, ligados com o ciclo de Manchas solares (Echer et al., 2003); no entanto, também pode estar associado à variabilidade do Dipolo do Atlântico (Clauzet \& Wainer, 1999), e ainda, a escala temporal de 20,2-22 anos, decorrente em alguns casos, da Oscilação Decadal do Pacífico (Mantua et al., 1997).

Altos valores de SPI caracterizando eventos extremos foram identificados em todas as capitais estudadas. Esses eventos ocorreram em muitos casos devido à ocorrência simultânea de várias escalas temporais que são responsáveis por anomalias pluviométricas, corroborando com Andreoli et al. (2004). Gershunov e Barnett (1998), e Da Silva (2017).

\section{$\underline{\text { Aracaju }}$}

$\mathrm{Na}$ análise de distribuição de eventos conforme o SPI para Aracaju (Figura 2a) foi quantificada 1 ocorrência de seca extrema, 3 de seca severa, 35 de seca moderada e 182 de seca leve; totalizando 221 ocorrências, que representa $34,11 \%$ dos eventos. Estes eventos secos (SPIs negativos) apresentaram-se em maior número, no entanto, com menor intensidade, atingindo o máximo de aproximadamente $-2,3$ em julho de 2013.

$\mathrm{Na}$ distribuição de eventos de chuvas registrou-se 53 ocorrências de chuva leve, 26 de chuva moderada, 25 de chuva severa e 28 de chuva extrema; resultando em um total de 132 casos de eventos de chuvas, que totalizou $20,37 \%$, tendo o maior volume de chuva registrado em setembro de 1964, alcançando o valor aproximado a $+6,0$ de SPI, ano em que ocorreu um La Niña moderado (CPTEC, 2018).

Os eventos de secas leves e moderadas apesar de não serem tão intensos apontam tendência de redução hídrica, ainda, podendo contribuir para novas ocorrências do evento, fazendo com que, dependendo da escala de tempo, as condições de umidade no solo fiquem desfavoráveis. A seca e o déficit de umidade têm impactos sociais, ambientais e econômicos, o que acarreta inumeráveis danos a todos os atingidos.

É importante acentuar que os 28 casos de chuva extrema ( $4,32 \%$ dos casos) foram superiores ao número de seca com a mesma intensidade $(0,15 \%)$, acontecimento que merece atenção

Da Silva, D. F., Lima, M. J. S., Souza Neto, P. F., Gomes, H. B., Silva, F. D. S., Almeida, H. R. R. C., Pereira, M. P. S., Costa, R. L. 
especial devido os episódios de fortes chuvas e implantação devida de medidas mitigadoras aos seus impactos.

A série temporal do SPI de Aracaju (Figura 2b) registrou picos de chuvas mais intensos entre 1964 a 1968. Este período associa-se à fase fria da Oscilação Decadal do Pacífico (ODP), em conjunto com eventos de El Niño Oscilação Sul (Figura 2c). Estes, em fases opostas, ocasionam anomalias de precipitação tanto positiva quanto negativa segundo Andreoli \& Kayano (2005) Apud Bonfim \& Da Silva (2018).

Costa (2015) ao utilizar o Índice de Anomalia de Chuva para o Ceará verificou que nos anos em que houve interação entre El Niño e ODP em fase quente, favoreceu-se a incidência de seca em quase todo o Estado.

Os registros de períodos de anos mais secos foram de 1961 a 1963 e de 2004 a 2014; os anos de 1963 e 2004 foram anos de atuação do fenômeno El Niño, responsável por ocorrência de secas no nordeste brasileiro. O SPI para Aracaju apresentou alta variabilidade entre seus valores negativos (secas) e positivos (chuvosos), tendo assim, poucos períodos com meses seguidos considerados normais (sem anomalias), como entre
1971-73 e de 1982-83.

Para Aracaju os maiores índices positivos da série de SPI (Figura 2c) foram encontrados entre 1964 e 1965, sugerindo que esse período foi marcado por ocorrência de alguns anos chuvosos anômalos. A causa destes aumentos anômalos deve-se possivelmente pela atuação conjunta de fenômenos meteorológicos de escalas temporais distintas: escala sazonal, interanual, entre 1-2 anos, de 7 anos ligada ao ENOS, escala de 11 anos, sendo esta a escala dominante na série (Figura 2d), e a escala de 20,2-22 anos (Figura 29b e c). A ocorrência simultânea de fenômenos de diferentes escalas temporais resulta em aumentos na precipitação (Rockwood \& Maddox, 1988). Todas as escalas atuantes mostraram-se com significância com exceção da escala sazonal (Figura 2d).

Entre os valores negativos de Precipitação pelo SPI para Aracaju, tem-se o ano de 2013 o menor valor, o qual não apresentou união de escalas temporais diferentes nem fenômeno com forte atuação, apenas vestígios da escala decadal. A ausência dos fenômenos e a não junção de escalas nas mesmas fases podem ser as possíveis causas de anos com valores de Precipitação baixos (Figura 2c).

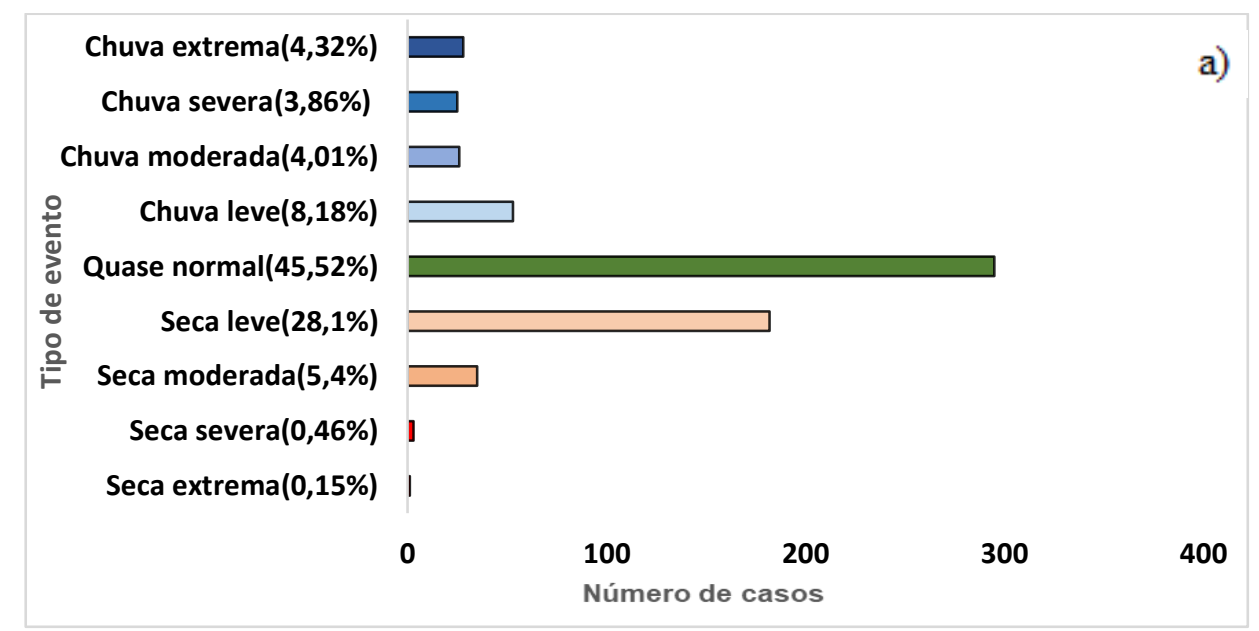

Figura 2: a) Distribuição da frequência dos eventos, por categoria do SPI, para Aracaju 8.00

b)

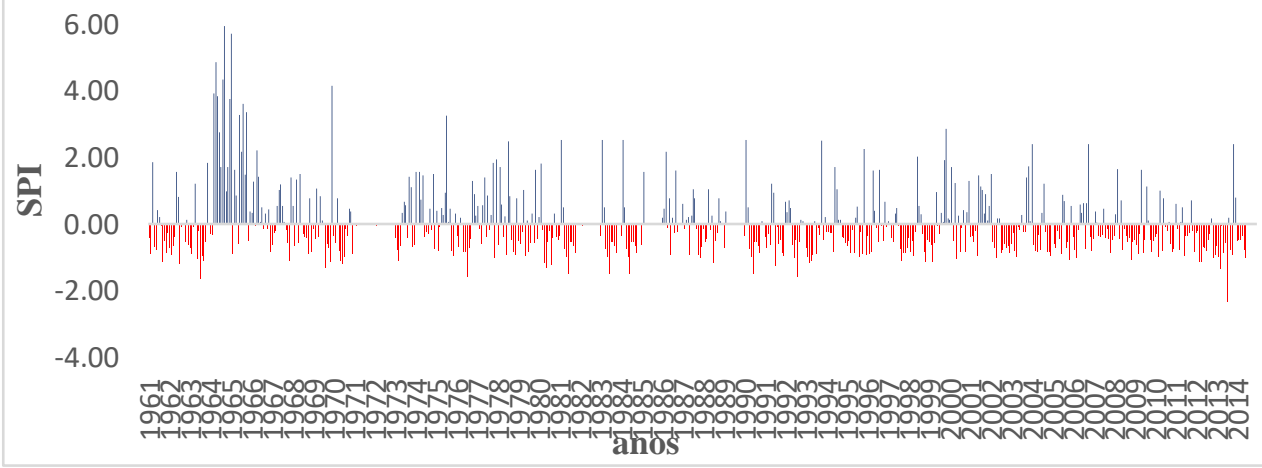

Figura 2: b) Série temporal do SPI para Aracaju.

Da Silva, D. F., Lima, M. J. S., Souza Neto, P. F., Gomes, H. B., Silva, F. D. S., Almeida, H. R. R. C., Pereira, M. P. S., Costa, R. L. 

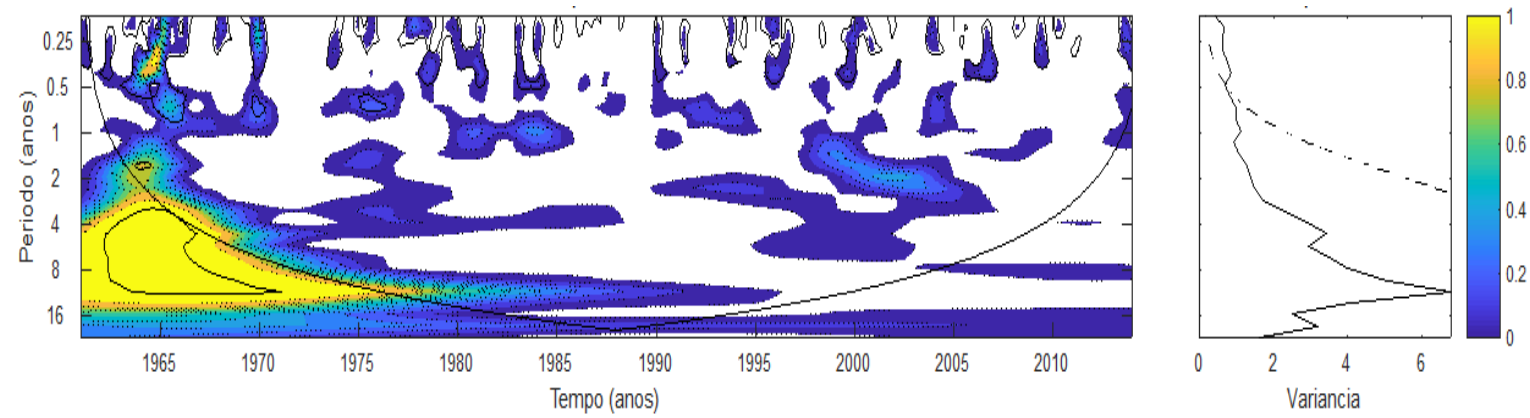

Figura 2: c) Espectro de potência de ondeleta (EPO) para SPI de Aracaju. A curva em forma de U representa o cone de influência, sob a qual o efeito de borda é importante; d) Espectro de potência global (EPG), com o contorno tracejado indicando que o EPG é significativo ao nível de confiança de $95 \%$.

\section{$\underline{\text { João Pessoa }}$}

Para a cidade de João Pessoa, a distribuição de frequência do SPI (Figura 3a) registrou, no período de estudo, 2 ocorrências de seca extrema, 12 de seca severa, 67 de seca moderada e 148 de seca leve; totalizando 228 eventos, que corresponde a 35,07\% dos eventos. Na distribuição de eventos de chuvas foram registrados 57 episódios de chuva leve, 48 de chuva moderada, 18 de chuva severa e 28 de chuva extrema; totalizando 151 ocorrências que corresponde a $23,12 \%$ dos eventos. O maior valor de SPI positivo registrado foi de +5 em fevereiro de 1989, ano que houve atuação do fenômeno La Niña de forte intensidade conforme CPTEC (2018) o que intensifica o evento de precipitação.

A maioria das secas foram de intensidade leve $(22,66 \%)$, seguida por seca moderada $(10,26$ $\%$ ), tendo somente $0,31 \%$ de seca extrema, corroborando com Macedo et al. (2010), que segundo seus resultados os eventos de seca mostrou-se mais frequentes que os eventos de chuvas, tendo duração de 14 meses, contudo a incidência de eventos chuvosos foram mais intensos, como resultados encontrados também por Bonfim \& Da Silva (2017).

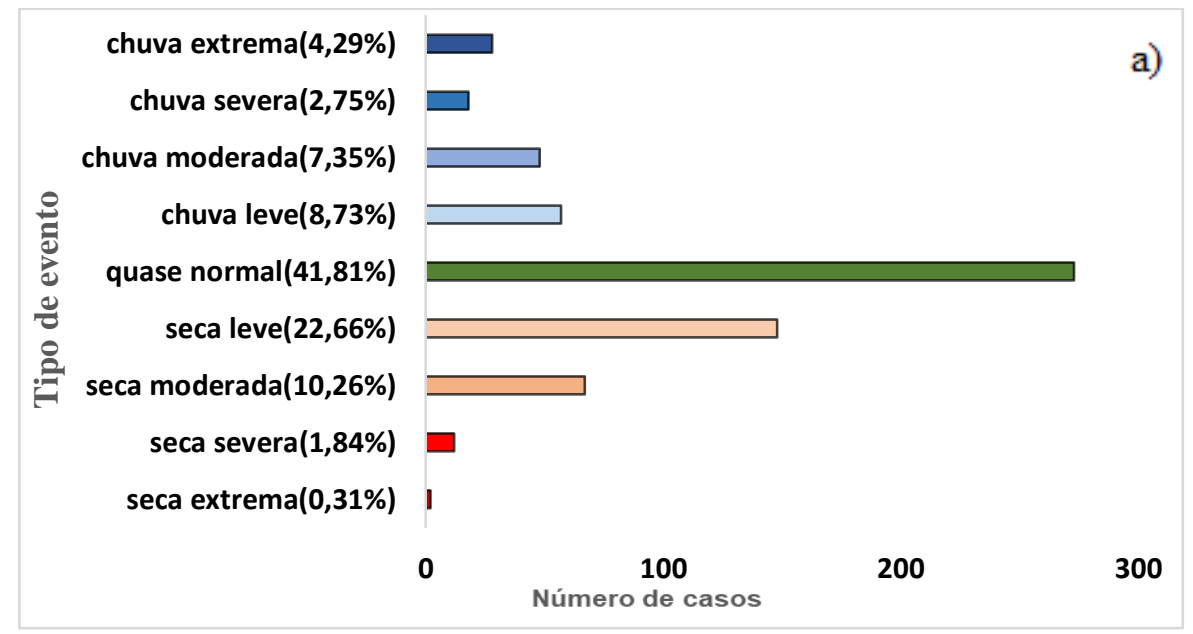

Figura 3: a) Distribuição da frequência dos eventos, por categoria do SPI, para João Pessoa

Para a série temporal do SPI (Figura 3b) ocorreram períodos chuvosos entre agosto de 1963 a março de 1964,1978 a 1979 , de 1989 a 1990 e de 2004 a 2011. Estes anos correspondem aos maiores valores de SPI $(>2,0)$ caracterizando precipitação de extrema intensidade, sendo o período de 63/64 transição entre El Niño fraco a uma La Niña moderada. O máximo pico de precipitação ocorreu entre jan/mai de 1989, associado a La Niña e coincidindo com a fase quente da ODP, contribuindo com um aumento na precipitação. Já os extremos negativos (seca severa a extrema) ocorreram principalmente em junho em 1972, maio de 1975, e atingindo valor máximo valor em julho de 2014.

Para cidade de João Pessoa os altos valores 
de SPI estão ligados a escala sazonal e interanual de 1-2 anos ligada ao ENOS (Figura 3c), além das escalas que se revelaram dominantes por estarem presentes em toda a série, as escalas de 11 anos e 7 anos, sendo dominante e secundaria, respectivamente.
Os baixos valores de SPI que ocorreram em 1972 e 1982 (Figura 3a) associam-se com a ocorrência da escala sazonal e interanual de 1-2 anos, escala de ENOS, ENOS estendido e escala de Dipolo do Atlântico (Figura 3b).

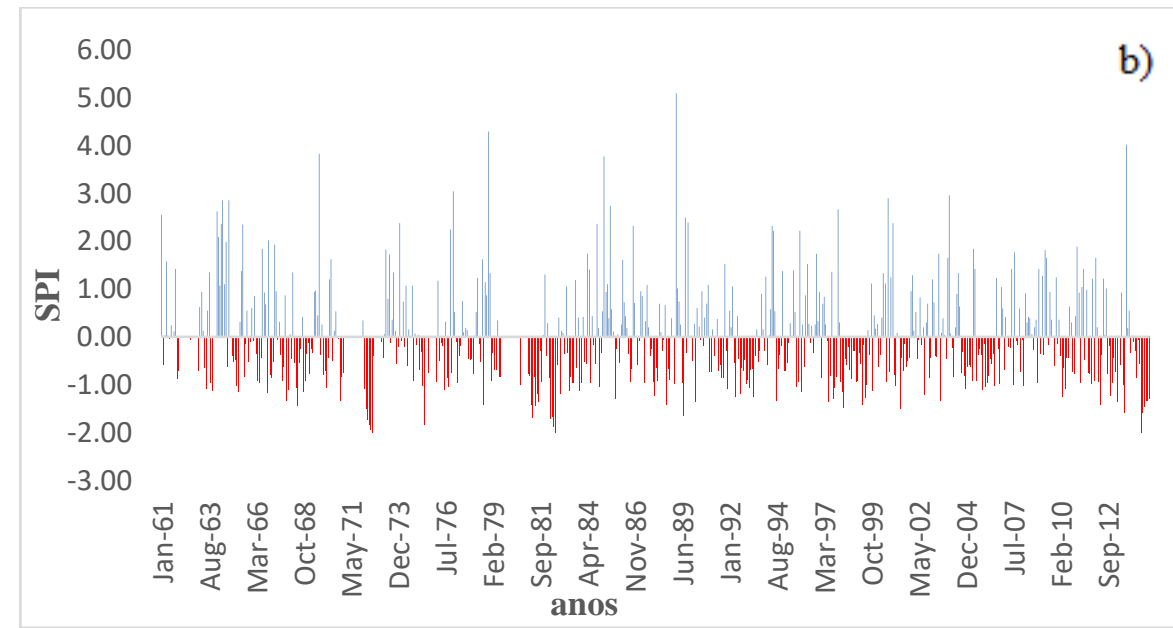

Figura 3: b) Série temporal do SPI para João Pessoa.
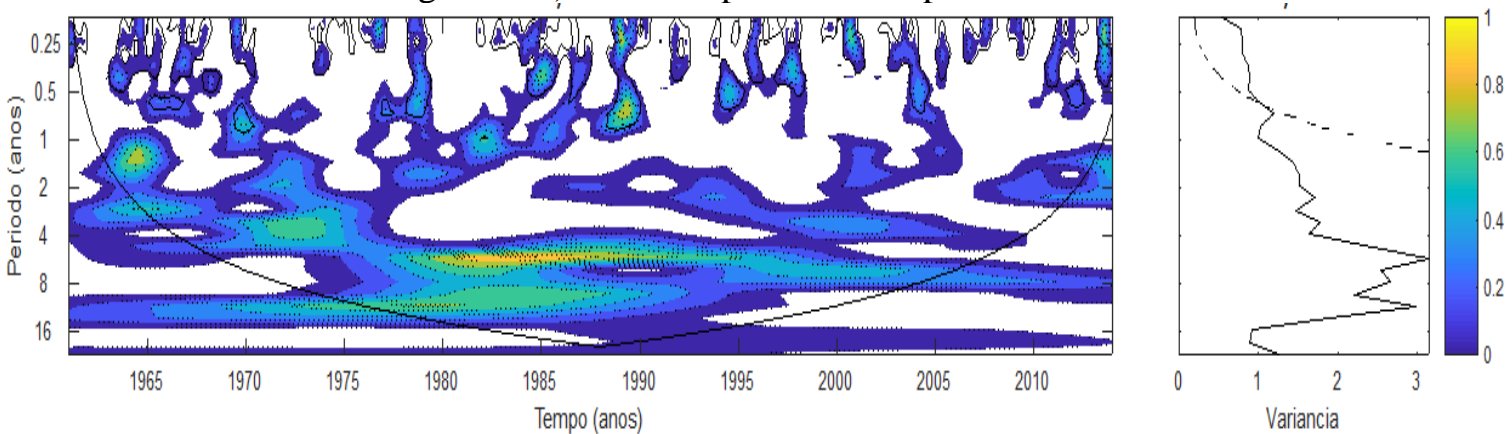

Figura 3: c) Espectro de potência de ondeleta (EPO) para SPI de João Pessoa. A curva em forma de U representa o cone de influência, sob a qual o efeito de borda é importante; d) Espectro de potência global (EPG), com o contorno tracejado indicando que o EPG é significativo ao nível de confiança de $95 \%$.

\section{Maceió}

Analisando a distribuição de eventos de acordo com o SPI para Maceió (Figura 4a) observaram-se 3 episódios de seca extrema, 16 ocorrências de seca severa, 65 de seca moderada e 148 de seca leve; resultando em 226 eventos de seca, correspondendo a 34,87\% dos episódios da estação de Maceió. Para a quantificação de eventos de chuvas foram apontados 57 episódios de chuva leve, 40 de chuva moderada, 25 de chuva severa e
32 de chuva extrema; um total de 154 ocorrências, que representa $23,77 \%$ dos eventos.

Dentre as capitais analisadas Maceió mostrou máximo registro de seca extrema, com 3 eventos, nos anos de 1982, 1983, e 1984. Esses anos, com exceção de 1984, foram anos de atuação do fenômeno El Niño segundo registros do CPTEC (2018), sendo esse, possivelmente o intensificador dos eventos; no ano de 1984 houve um La Niña de baixa intensidade (CPTEC, 2018). 


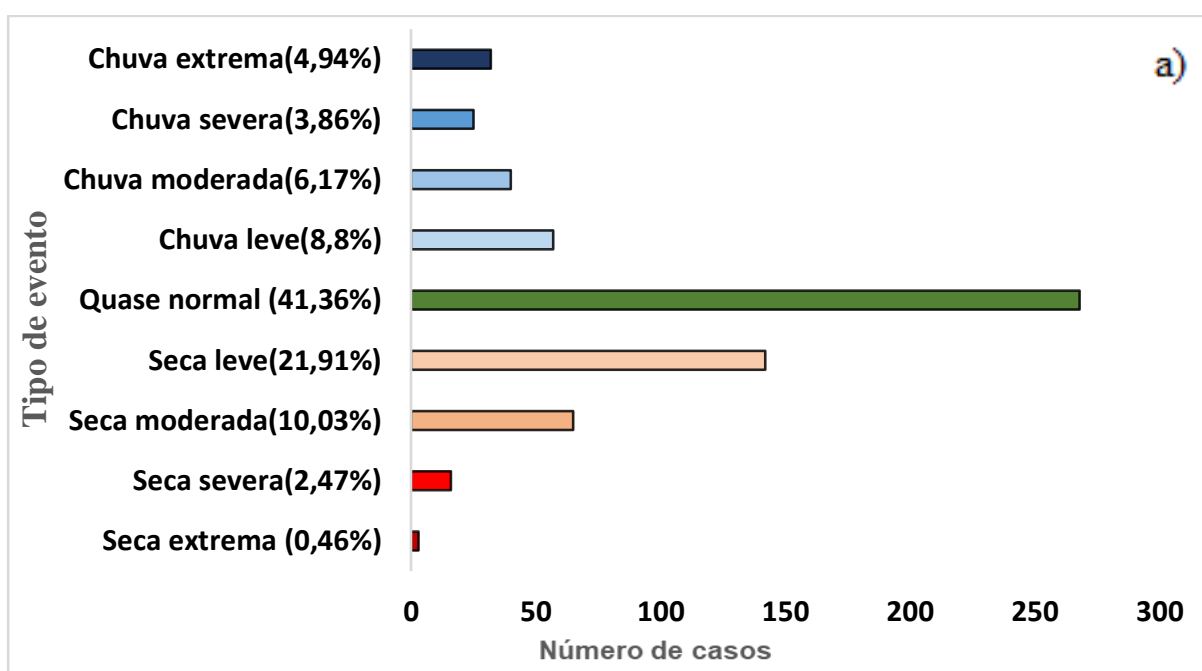

Figura 4: a) Distribuição da frequência dos eventos, por categoria do SPI, para Maceió

Os anos que caracterizaram chuvas para Maceió (Figura 4b) foram os anos de 1980, 1994, 2002, 2004, quando os valores de SPI foram superiores a 2 , o que ocasiona alta intensidade de precipitação, acarretando grandes acumulos de chuvas, contribuindo com inundações e enchentes. Todos os anos estão associados a casos de El Niño (EN) evidenciando um comportamento não convencional do fenômeno. Para Sousa et al., (2016) nem todos os eventos de El Niño ocasionaram secas extremas, assim como nem todos os eventos de La Niña produziram chuvas acima da média. Isto dá-se pela existência do fenômeno chamado por diversos autores de ENOS Modoki, que, a depender da estação e localidade, causa impactos/efeitos distintos, por vezes contrários ao ENOS convencional (Ashok et al., 2007; Tedeschi, 2013). Os extremos secos foram registrados entre 1981 a 1984, sendo 1982 e 1983 anos de atuação do El Niño (CPTEC, 2018).

Em Maceió os picos de máximos valores positivos de SPI (Figura 4c) deram-se em 1964, 1970, 1977, 1989, 1995, 2001 e 2002, sendo esses, de atuação da escala de 11 anos, o que evidencia a relação entre a precipitação local e o Dipolo do Atlântico de acordo com Souza et al. (1998) e Clauzet \& Wainer (1999). Essa escala também está associada com o ciclo de Manchas solares conforme Echer (2003); Molion (2005). Ainda essa escala mostrou-se a dominante em toda a série de SPI de Maceió.

A escala secundária foi a escala decadal (20 a 22 anos) (Figura 4c e 4d) que esteve presente ao longo da série e seus ciclos resultaram em baixos valores de Precipitação como em 1971, 1991 e 2011 (Figura 4b).

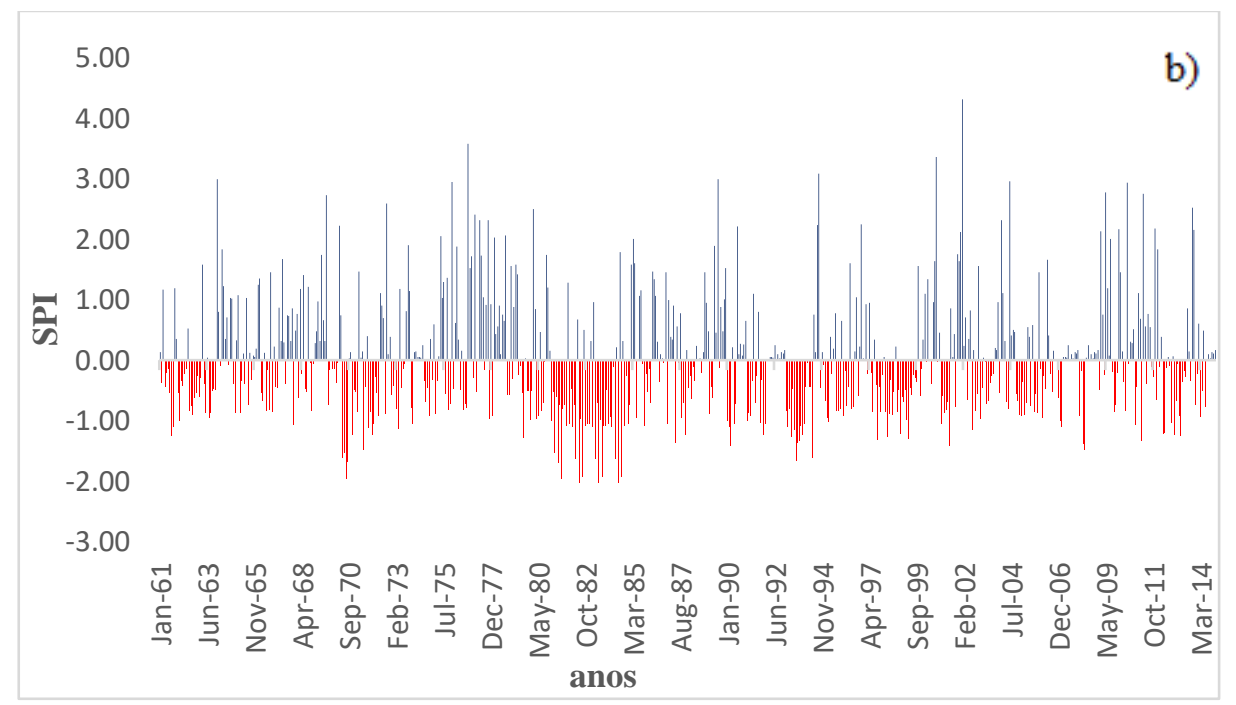

Figura 4: b) Série temporal do SPI para Maceió. 

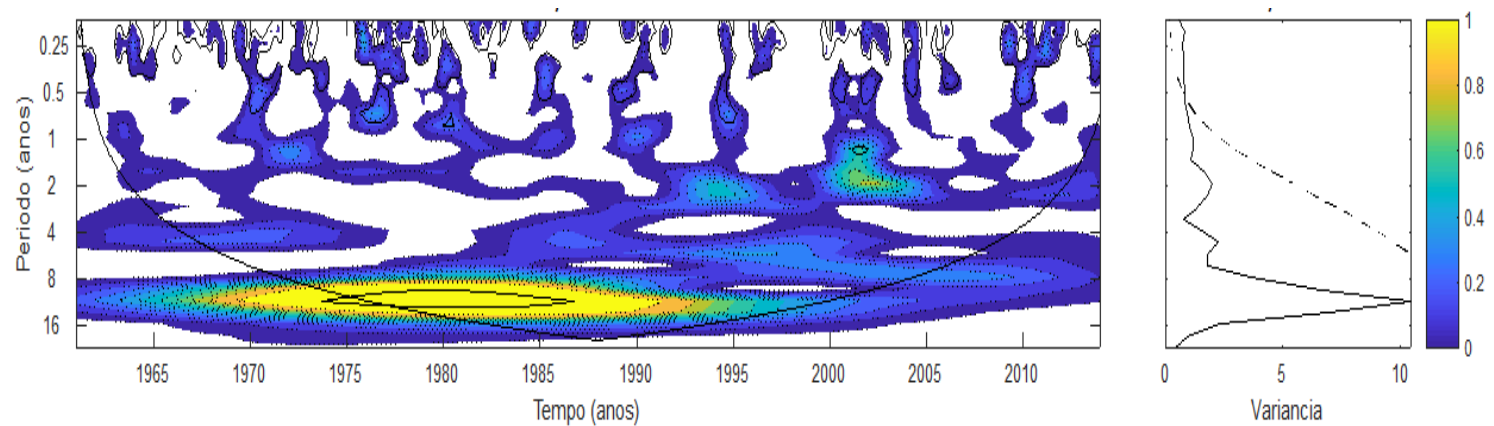

Figura 4: c) Espectro de potência de ondeleta (EPO) para SPI de Maceió. A curva em forma de U representa o cone de influência, sob a qual o efeito de borda é importante; d) Espectro de potência global (EPG), com o contorno tracejado indicando que o EPG é significativo ao nível de confiança de $95 \%$.

$\underline{\text { Natal }}$

Para a cidade de Natal (Figura 5a) a distribuição de frequência do SPI quantificou 9 ocorrências de seca severa, 66 de seca moderada e 149 de seca leve, contudo não houve registro de seca extrema (valores de SPI <-2,0); totalizando 224 ocorrências, que corresponde a $35 \%$ dos eventos. Na quantificação de eventos de chuvas notou-se 63 ocorrências de chuva leve, 36 de chuva moderada, 16 de chuva severa e 33 de chuva extrema; um total de 148 registros, equivalente a $22,87 \%$ dos eventos.

Os SPI secos com destaque foram: 1961 a 1963, de 1969 a 1971, 1983, 1991 a 1993, 2012 a 2013, onde os meses com eventos severos de seca ocorreram entre junho de 1978, março de 1983, maio de 2013.

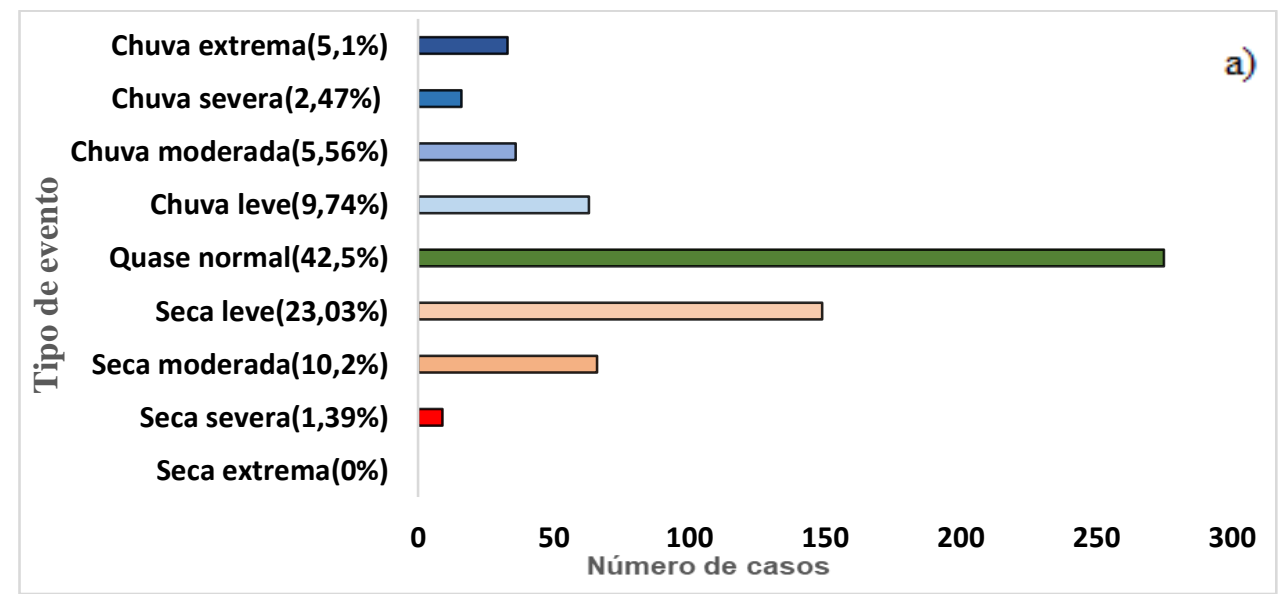

Figura 5: a) Distribuição da frequência dos eventos, por categoria do SPI, para Natal.

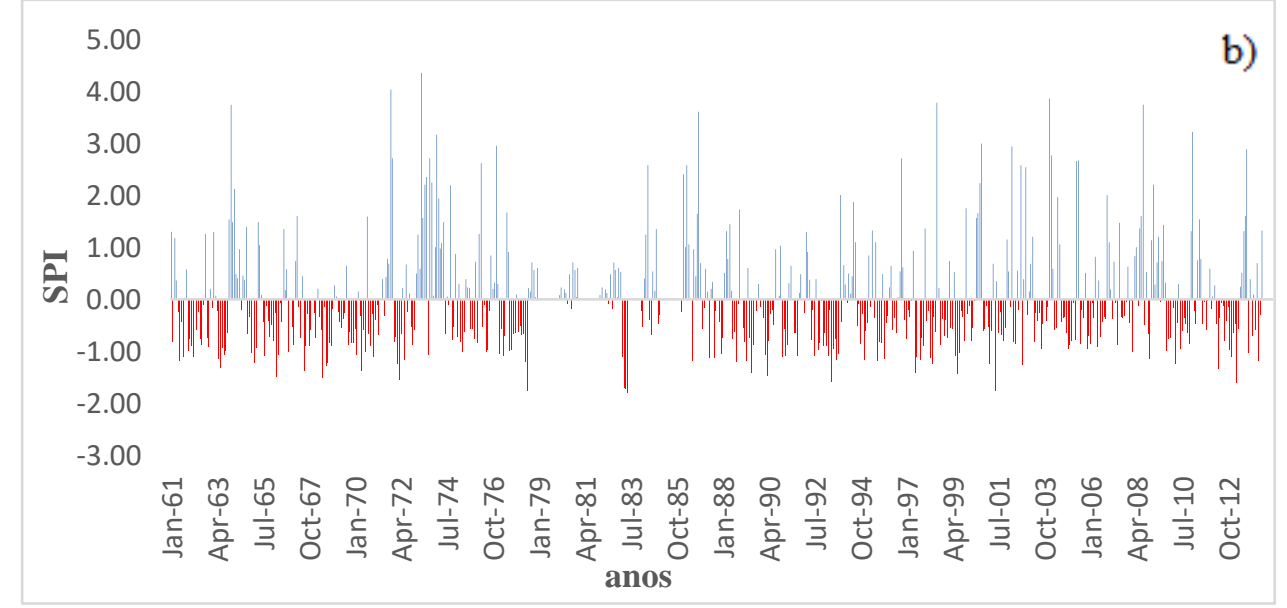

Figura 5: b) Série temporal do SPI para Natal.

Da Silva, D. F., Lima, M. J. S., Souza Neto, P. F., Gomes, H. B., Silva, F. D. S., Almeida, H. R. R. C., Pereira, M. P. S., Costa, R. L. 

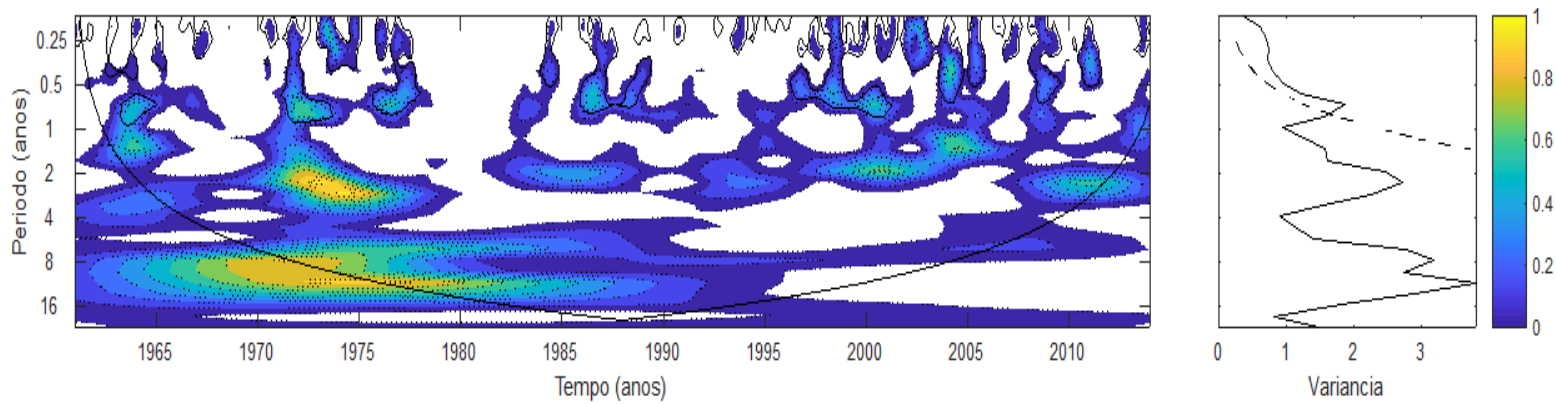

Figura 5: c) Espectro de potência de ondeleta (EPO) para SPI de Natal. A curva em forma de U representa o cone de influência, sob a qual o efeito de borda é importante; d) Espectro de potência global (EPG), com o contorno tracejado indicando que o EPG é significativo ao nível de confiança de $95 \%$.

A cidade apresentou diversas ocorrências de valores positivos de SPI (Figura $5 b$ ); os eventos de chuvas mais intensas para Natal ocorreram em dezembro 1963, outubro de 1971, em abril de 1973 atingiu-se o valor máximo de $+4,36$. Ainda nos anos 1984, 1986, 1998, 2000, 2004 ocorreram altos valores de SPI. Evento de alta intensidade de precipitação causa impactos maiores em grandes cidades, devido à área impermeabilizada, dificultando a infiltração da agua no solo e aumentados o escoamento superficial contribuindo assim como enchentes e alagamentos. O fenômeno La Niña foi o responsável por potencializar extremos de chuva em 1998, 2000, e 2008,

\section{$\underline{\text { Recife }}$}

Na distribuição de frequência do SPI para a cidade de Recife (Figura 6a), verificaram-se 2 casos de seca extrema, 9 ocorrências de seca severa, 75 de seca moderada e 163 de seca leve; totalizando 249 ocorrências, que corresponde a $38,42 \%$ dos eventos. Na distribuição de eventos de chuvas observou-se 65 ocorrências de chuva leve, 56 de chuva moderada, 28 de chuva severa e 28 de chuva extrema; totalizando 177 casos, equivalente a 27,32\% dos eventos, mostrando que a cidade é a maior em ocorrências de eventos chuvosos.

Eventos classificados como chuvosos pelo SPI foram de 1961 a 1962, de 1965 a 1966, de 1985 conforme resultados encontrados por Nascimento et al. (2017).

A série de Precipitação de Natal teve a escala temporal de 11 anos como escala dominante, estando atuante desde 1961 até 1995 (Figura 5c e 5d). Já a escala secundária foi a de 8 anos que influenciou a série ao longo de todo período.

Assim como nas cidades anteriores, as interações simultâneas de diferentes escalas temporais explicam os altos valores de Precipitação para Natal (Figura 5c), como também as influências de ENOS, ENOS estendido, Dipolo do Atlântico, Manchas solares e ODP.

a 1987, de 1994 a 1995 , de 2000 a 2001, 2011 e 2013. Chuva com extrema intensidade foi observada em 1970, 1980, 1991, 1994; todos estes episódios ocorreram sub a influência do El Niño, sendo este, no entanto um ENOS não convencional (Tedeschi, 2013).

Foram registrados $78 \mathrm{~mm}$ de precipitação no dia 19 de abril de 2011 em Recife, onde cerca de $63 \%$ do total ocorreu em apenas 2 horas conforme registros do INMET (2011) citado por Fialho \& Molion (2011), episódios como esse acarretam prejuízos inesperados aos afetados e responsáveis pelo planejamento, logo vê-se a necessidade de detectar e monitorar eventos secos/chuvosos. 


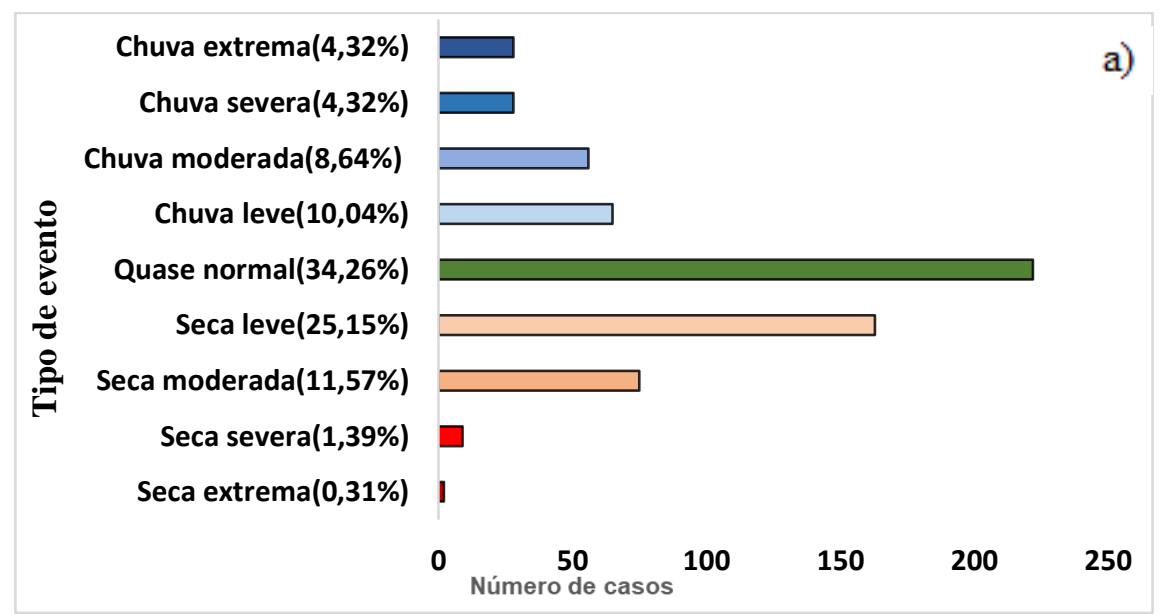

Figura 6: a) Distribuição da frequência dos eventos, por categoria do SPI, para Recife.

Anos secos (Figura 6b) com destaque foram 1968, 1983, 1999, 2001 e 2014. Os eventos secos de moderado a extremos ocorreram também em anos de El Niño, como 1983, 1987, 1992, 1993.

A escala dominante na série de Precipitação em Recife (Figura 6c e 6d) foi a decadal de 2 anos, no entanto, não apresentou significância estatística (Figura 6d). Os anos 1964,
1970, 1973, 1981, 1987, 1991, 2000 e 2011 foram anos com extremos de precipitação em decorrência dessa escala dominante. Além disso, a escala secundária de 8 anos (ENOS estendido), atuando de 1961 a 1975 , de 1992 a 2005 A escala de 11 anos (do Dipolo do Atlântico e das Manchas solares) também foi escala secundária de 1977 a 2010 (Figura 6 c e 6d)

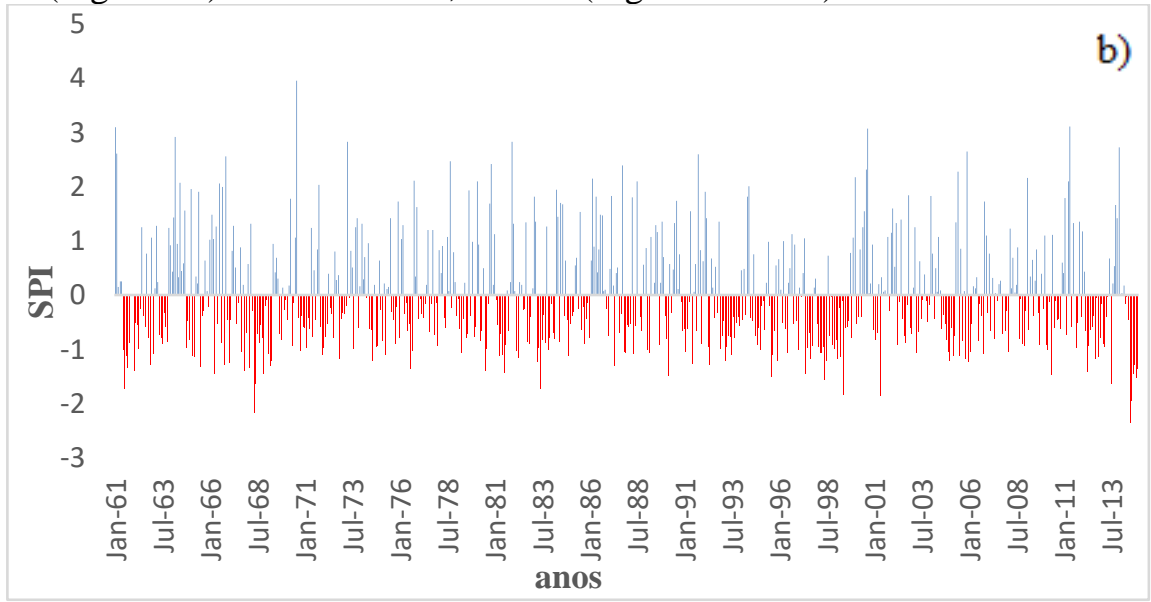

Figura 6: b) Série temporal do SPI para Recife.
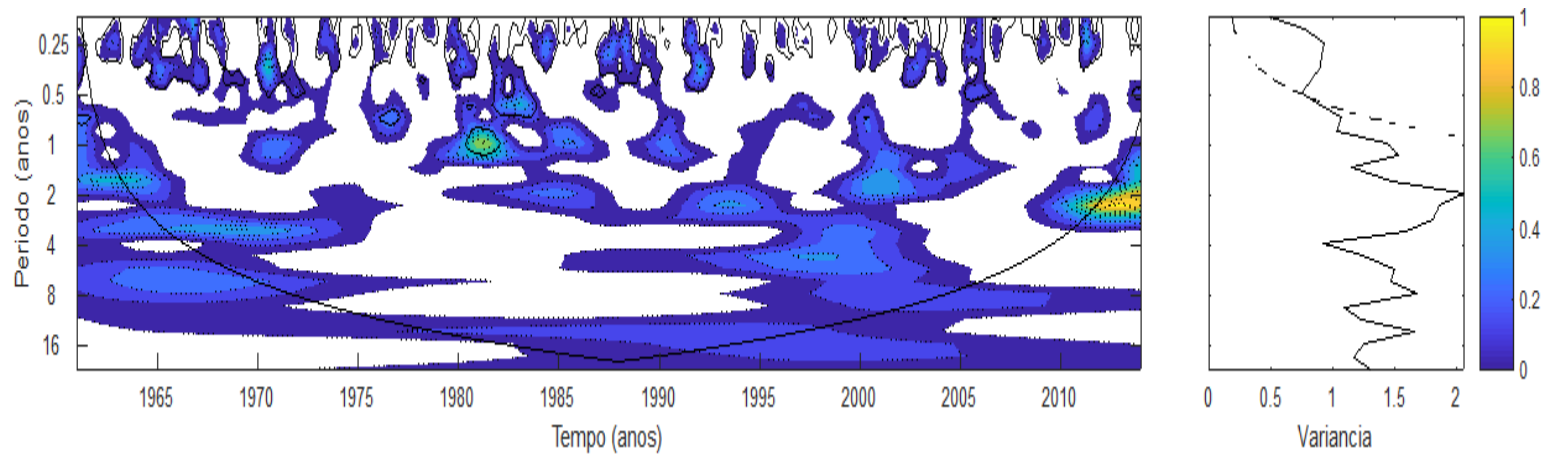

Figura 6: c) Espectro de potência de ondaleta (EPO) para SPI de Recife. A curva em forma de U representa o cone de influência, sob a qual o efeito de borda é importante; d) Espectro de potência global (EPG), com o contorno tracejado indicando que o EPG é significativo ao nível de confiança de $95 \%$. 
$\underline{\text { Salvador }}$

A distribuição de frequência do SPI para Salvador (Figura 7a) apresentou um total de $34,25 \%$ de evento de secas, que corresponde a 222 registros. Foram observadas: 1 ocorrências de seca extrema, 12 de seca severa, 70 de seca moderada e 139 de seca leve. Na distribuição de eventos de chuvas foram notados 57 episódios de chuva leve, 44 de chuva moderada, 20 de chuva severa e 33 de chuva extrema; totalizando 157 ocorrências, que corresponde a $23,78 \%$ dos eventos.

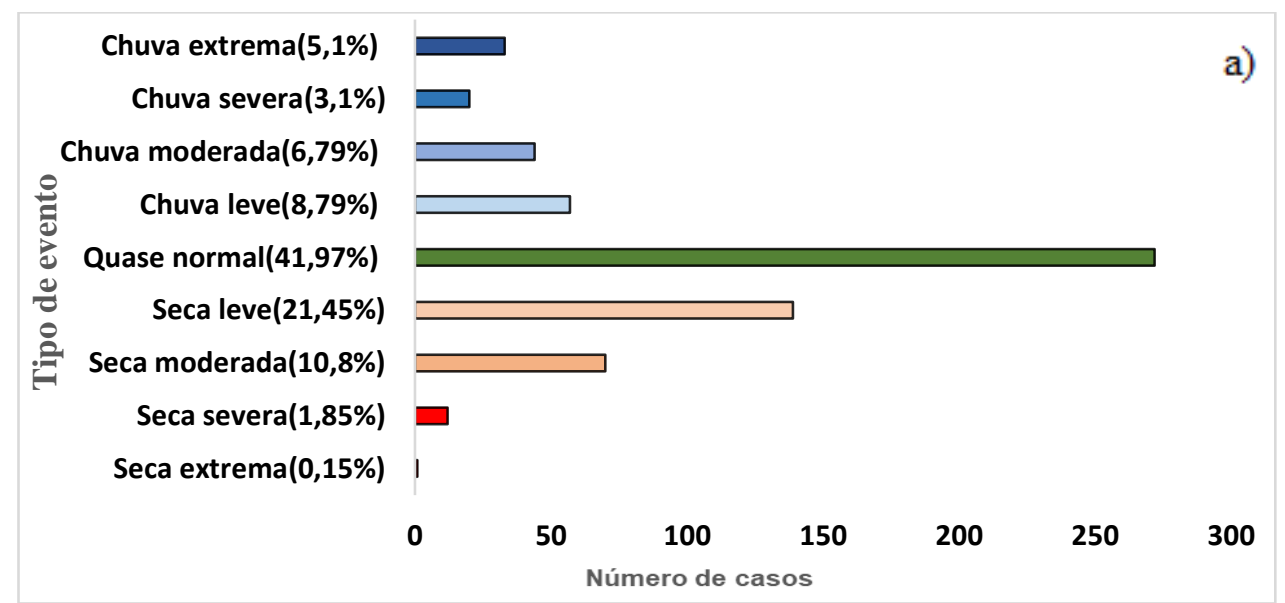

Figura 7: a) Distribuição da frequência dos eventos, por categoria do SPI, para Salvador.

Para Salvador chuva extrema pelo SPI (Figura 7b), ocorreu em diversos períodos, principalmente em julho de 2010 que foi o evento mais forte, atingindo o valor de SPI $+4,24$. Períodos chuvosos em destaque foram 1963 a 1965, de 1973 a 1974, de 1999 a 2001 e 2006. Em boa parte dos episódios caracterizados como extemos chuvosos ocorreram em anos de El Niño, demonstrando ainda mais seu comportamento não convencional, como apontado por Ashok et al., 2007 e Tedeschi (2013) para ENOS Modoki.

Os períodos secos que mais chamaram atenção e causaram mais prejuízos econômicos foram 1961 a 1962, 1979 a 1981, 1998, de 2007 a 2013, que apresentaram valores negativos de SPI, mesmo tendo ocorridos chuvas extremas em 2010. Esses resultados corroboram com os encontrados

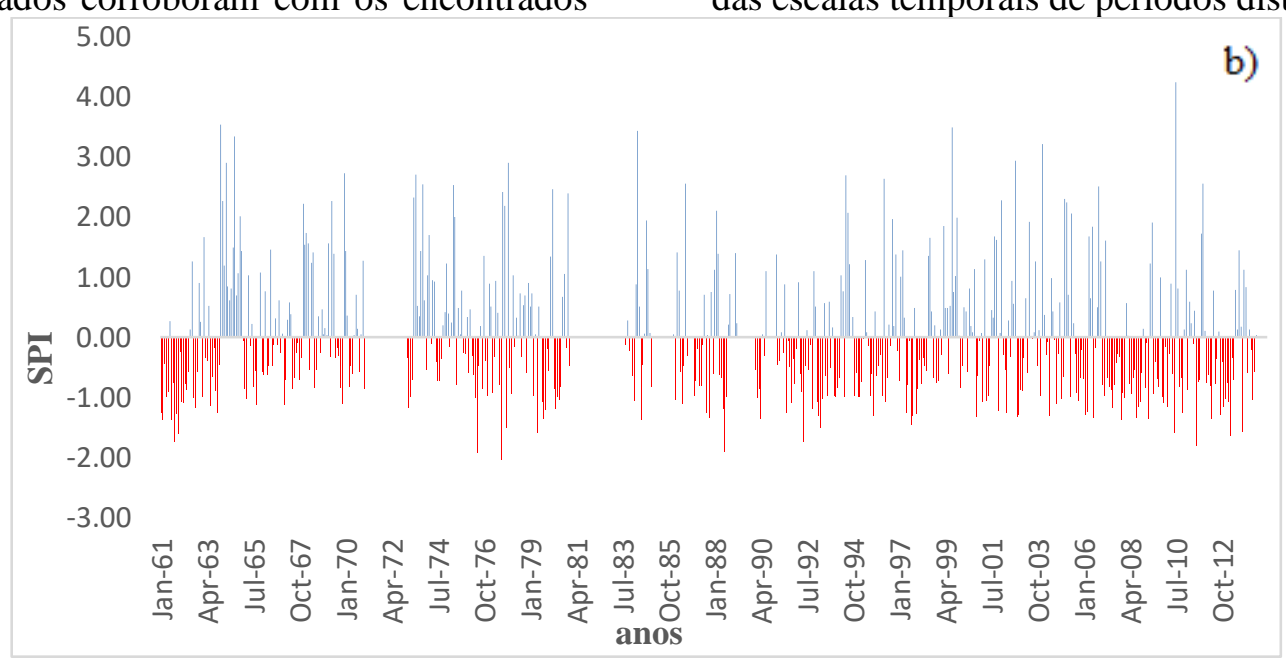

Figura 7: b) Série temporal do SPI para Salvador. por Sousa et al. (2016), para a Bahia.

Para Salvador, os principais extremos de precipitação (Figura 34a) foram observados nos índices de Precipitação em 1964, 1977/78, 1984, 1994, 2000, 2010/11. Esses anos correspondem a ciclos de fenômenos climáticos como ENOS, Dipolo do Atlântico, Ciclo de manchas solares e Oscilação Decadal do Pacífico, exceto 1984, quando ocorreu somente variabilidade semestral e escala de 11 anos associado ao Dipolo do Atlântico. O extremo pluviométrico de 1964, por exemplo, ocorreu em função da junção de várias escalas temporais (Figuras $7 \mathrm{c}$ e $7 \mathrm{~d}$ ), o que acentua/intensifica os totais pluviométricos locais. Os outros extremos (1977/78, 1994, 2000, 2010/11) também foram causados pela interação das escalas temporais de períodos distintos.

b) 

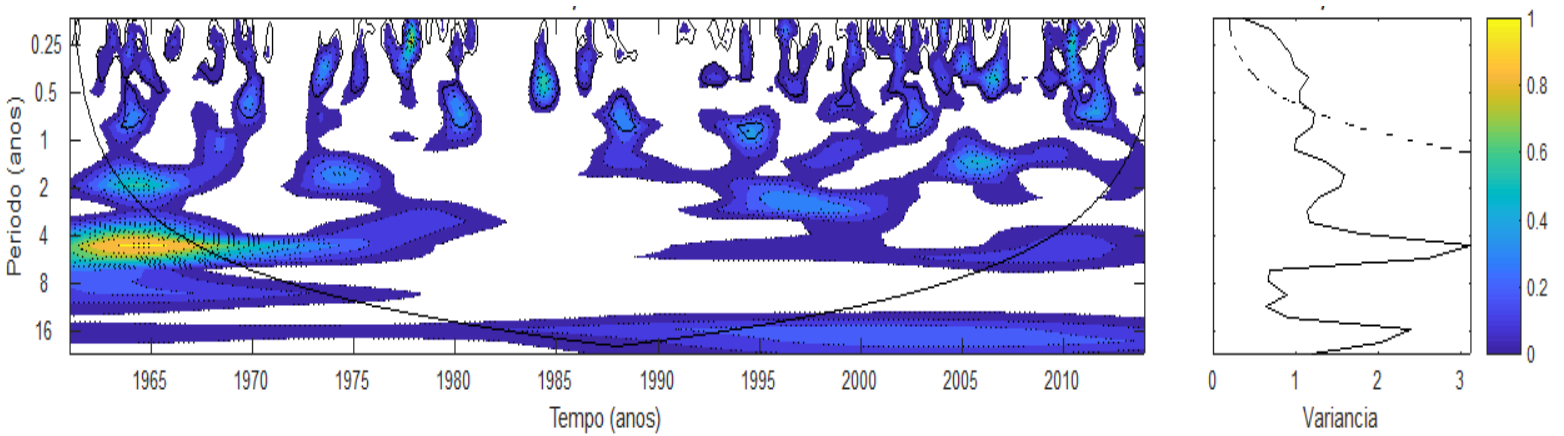

Figura 7: c) Espectro de potência de ondeleta (EPO) para SPI de Salvador. A curva em forma de U representa o cone de influência, sob a qual o efeito de borda é importante; d) Espectro de potência global (EPG), com o contorno tracejado indicando que o EPG é significativo ao nível de confiança de 95\%.

\section{Conclusão}

Visando a importância do conhecimento sobre extremos climáticos, o presente estudo avaliou quantitativamente os eventos secos e chuvosos na região Leste nordestina através do índice de precipitação padronizada (SPI).

A quantidade de secas leves a moderadas foram maiores que os de chuva leve a moderada para todas as cidades analisadas. Os episódios de secas leves ultrapassam o total de todas as respectivas classes de chuvas juntas, no entanto, casos com intensidade extrema de precipitação foram mais persistentes quando comparado aos eventos de seca com a mesma intensidade. Recife mostrou-se a cidade com máximas ocorrências de eventos chuvosos.

A maioria dos eventos de chuva e seca estão associados, principalmente, ao fenômeno ENOS, no entanto observou-se um comportamento convencional do fenômeno, fato relacionado ligado ao tipo de ENOS, Canônico ou Modoki.

O Índice de Precipitação Normalizada mostrou-se bastante capaz para quantificar os eventos secos e chuvosos, como também monitorando déficit/excesso de precipitação, revelando ser uma ferramenta apta à mitigação de secas, pois a identificação antecipada de eventos extremos e o seu monitoramento resultam em um conjunto de informações que auxiliam distintos setores, mitigando os impactos que esses possíveis eventos possam causar.

$\mathrm{Na}$ identificação de causas climáticas, através das Análises de Ondeletas, foram apontadas as escalas temporais de 1 a 2 anos (em todas as capitais) associada ao ciclo de ENOS, a escala temporal de 7 a 8 anos, relacionadas com eventos ENOS estendido, a escala de 8 a 11 anos do Dipolo do Atlântico, a de 11 anos do ciclo de Manchas solares, e a escala temporal de 20,2-22 anos da Oscilação Decadal do Pacífico. A junção ou ausência desses fenômenos dessas escalas temporais também diminuiu ou potencializou os eventos extremos.

\section{Referências}

Aceituno, P. 1988. On the functioning of the southern oscillation in the South American sector. Part1: surface climate, Monthly Weather Review, 116, 505-524.

Andreoli, R. V.; Kayano, M. T.; Guedes, R. L.; Oyama, M. D.; Alves0, M. A. S. 2004. A influência da temperatura da superfície do mar dos Oceanos Pacífico e Atlântico na variabilidade de precipitação em Fortaleza, Revista Brasileira de Meteorologia, 19, 337344.

Ashok, K.; Behera, S. K.; Rao, S. A.; Weng, H. Y.; Yamagata, T. 2007. El Niño Modoki and its possible teleconnection. Journal of Geophysical Research, 112, 1-2.

Anjos, R., Nóbrega, R., Araújo, F., \& Rocha Filho, G. (2016). Spacial Distribution of Rain Types In Pernambuco With The Usage Of Remote Sensing. Journal of Hyperspectral Remote Sensing, 6(3), 154-163. doi:https://doi.org/10.5935/22372202.20160016

Bonfim, O. E. T.; Da Silva, D. F. 2018. Influência do ENOS canônico e modoki sobre a ocorrência de eventos extremos na bacia hidrográfica Aguapeí-Peixe (SP). Revista Ibero-Americana de Ciências Ambientais, 9.

Clauzet, G.; Wainer, I. 1999. Identificação da variabilidade de baixa frequência em algumas regiões da costa sudeste-nordeste do Brasil. Revista Brasileira Oceanografia, 47, 69-78.

Costa, J. A. 2015. Distribuição Espaço-Temporal do Índice de Anomalia de Chuva Para o Estado 
do Ceará. Universidade Federal do Cariri, Crato.

Da Silva, D. F. 2009. Análise de aspectos climatológicos, agroeconômicos, ambientais e de seus efeitos sobre a bacia hidrográfica do rio Mundaú (AL E PE), março de 2009, 212 p., Tese de Doutorado em Recursos Naturais, UFCG, Campina Grande (PB).

Da Silva, D. F.; Sousa, F. de A. S. DE; Kayano, M.T. 2010. Escalas temporais da variabilidade pluviométrica na bacia hidrográfica do rio mundaú. Revista Brasileira de Meteorologia, 25, 147-155.

Da Silva, D. F. 2014. Previsão Hidro-climática para prevenção de desastres naturais do leste do Nordeste do Brasil utilizando análises estatísticas avançadas. Projeto Edital Universal - CNPq, p. 4-21.

Da Silva, D. F. 2017. Aplicação de Análises de Ondaletas para Detecção de Ciclos e Extremos Pluviométricos no Leste do Nordeste do Brasil. Revista Brasileira de Meteorologia, 32, 187198.

Echer, E.; Rigozo, N. R.; Nordemann, D. J. R.; Vieira, L. E. A.; Prestes, A.; Faria, H. H. 2003. $\mathrm{O}$ número de manchas solares, índice da atividade do sol. Revista Brasileira de Ensino de Física, 25, n. 2.

Fialho, W. M. B.; Molion, L. C. B. 2011. Estudo de caso de chuvas extremas no NEB: Recife (PE) Abril de 2011. Universidade Federal de Alagoas - Instituto de Ciências Atmosféricas.

Gershunov A, Barnett, T. P. 1998. Interdecadal modulation of ENSO teleconnections. Bulletin of the American Meteorological Society, 79: 2715-2725.

Guedes, R.V. S.; Macedo, M. J. H.; Sousa, F. A. S. 2012. Análise espacial de eventos de secas com base no índice padronizado de precipitação e análise de agrupamento. Revista Brasileira de Ciências Ambientais, 1, 55-65.

Instituto Brasileiro de Geografia e Estatística. População do Nordeste, 2010. Disponível em: www.ibge.gov.br. Acesso em: 19 nov. 2018.

Instituto Nacional de Pesquisas Espaciais. Centro de Previsão de Tempo e Estudos Climáticos CPTEC. La Niña. El Niño. 2018. Disponível em: http://enos.cptec.inpe.br/ Acesso em 25/11/2018.

Loureiro, R. S.; Saraiva, J. M.; Saraiva, I.; Senna, R. C.; Fredó, A. S. 2014. Estudo dos Eventos Extremos de Precipitação Ocorridos em 2009 no Estado do Pará. Revista Brasileira de Meteorologia, 29, 83-94.
Kousky, V. E.; Chu, P. S. 1978. Fluctuations in annual rainfall for northeast Brazil, Journal of The Meteorological Society of Japan, 56, 457466.

Macedo, M. J. H.; Guedes, R. V. S.; Souza, F. A. S.; Dantas, F. R. C. 2010. Análise do índice padronizado de precipitação para o estado da Paraíba, Brasil. Ambi-Agua, Taubaté, 5, 204214.

Mantua, N. J.; Hare, S. R.; Zhang, Y.; Wallace, J. M.; Francis, R. C. 1997. A Pacific interdecadal climate oscillation with Impacts on salmon production, Bulletin American Meteorological Society, 78, 1069-1079.

Marengo, J. A. 2017. Mudanças climáticas, Condições Meteorológicas Extremas e Eventos Climáticos no Brasil. Disponível em: $<$ http://www.fbds.org.br/cop15/FBDS_Mu dancasClimaticas.pdf $>$. Acesso em: 31-082017.

Mckee, T. B.; Doesken, N. J.; Kleist, J. 1993. The relationship of drought frequency and duration to times scale. In: Conference on Applied Climatology, 8, 1993, Boston. Anais... American Meteorological Society, Boston: Preprints, p. $179-184$.

Molion, L. C. B. 2005. Aquecimento global, El Niños, manchas solares, vulcões e oscilação decadal do Pacífico. Revista Climanálise, Cachoeira Paulista, 3, 1-5.

Morettin, P. A. 1999. Ondas e Ondeletas: Da Análise de Fourier à Análise de Ondeletas, EDUSP, 193 P.

Nascimento, F. C. A.; Braga, C. C.; Araújo, F. R. C. D. 2017. Análise Estatística dos Eventos Secos e Chuvosos de Precipitação do Estado do Maranhão. Revista Brasileira de Meteorologia, 32, 375-386.

Oliveira, J., de Medeiros, B., da Silva, J., Moura, G., Lins, F., Nascimento, C., \& Lopes, P. (2017). Space-temporal evaluation of biophysical parameters in the High Ipanema watershed by remote sensing. Journal of Hyperspectral Remote Sensing, 7(6), 357-366. doi:https://doi.org/10.29150/jhrs.v7.6.p357366

Rockwood, A. A.; Maddox, R. A. 1988. Mesoscale and synoptic scale interactions leading to intense convection: The case of June, 1982.Weatherand Forecasting, 3, 51-68.

Santos, S. R. Q.; Braga, C. C.; Sansigolo, C. A.; Santos, A. P. P. 2017. Determinação de Regiões Homogêneas do Índice de Precipitação Normalizada (SPI) na Amazônia Oriental. 
Revista Brasileira de Meteorologia, 32, 111122.

Santos, S. R. Q.; Braga, C. C.; Santos, A. P. P.; Brito, J. I. B.; Campos, T. L. O. B. 2014. Classificação de eventos extremos de precipitação em múltiplas escalas de tempo em Belém-PA: Utilizando o índice de precipitação normalizada. Revista Brasileira de Geografia Física, 7, 628-635.

Santos, S. R. Q.; Sansigolo, C. A.; Neves, T. T. A. T.; Campos, T. L. O. B.; Santos, A. P. P. 2017. Frequências dos Eventos Extremos de Seca e Chuva na Amazônia Utilizando Diferentes Bancos de Dados de Precipitação. Revista Brasileira de Geografia Física, 10, 468-478.

Sousa, F. A. S.; Macedo, M. J. H.; Guedes, R.V. S.; Silva, V. P. R. 2016. O Índice de Precipitação Padronizada (IPP) na identificação de extremos de chuvas e secas na bacia do rio Paraguaçu (BA). Revista Ambiência, Guarapuava, 12, 707-719.

Souza, E. B.; Brabo Alves, J. M.; Nobre, P. 1998. Anomalias de precipitação nos setores norte $\mathrm{e}$ leste do Nordeste brasileiro em associação aos eventos do padrão de dipolo observados na bacia do atlântico tropical. Revista Brasileira de Meteorologia, 13, 45-55.

Tedeschi, R. G. 2013. As Influências de Tipos Diferentes de ENOS na Precipitação e nos seus Eventos Extremos Sobre a América do Sul Observações, Simulações e Projeções. 2013. 224 p. Tese (Doutorado em Meteorologia) Instituto Nacional de Pesquisas Espaciais. São José dos Campos.

Weng, H.; Lau, K-M. 1994. Wavelets, period doubling, and time-frequency localization with application to organization of convection over the Tropical Western Pacific. Journal of the Atmospheric Sciences, 51, 2523-2541.

Uliana, E. M.; Dos Reis, E. F.; De Souza A. P.; Da Silva, J. G. F. e Xavier, A. C. 2015. Utilização do Índice de Precipitação Padronizado para a Região Norte do Estado do Espírito Santo. Revista Irriga, Botucatu, 20, 414-428. 